\title{
Beyond the Expected-Residual Risk and Cases of Overload in the Context of Managing Alpine Natural Hazards
}

\author{
Sönke Hartmann ${ }^{1}$ Lydia Pedoth $^{1} \cdot$ Cristina Dalla Torre $^{2} \cdot$ Stefan Schneiderbauer $^{1,3}$
}

Accepted: 18 October 2020/Published online: 22 January 2021

(C) The Author(s) 2021

\begin{abstract}
Structural protection measures are designed to protect the population and infrastructure against natural hazards up to a specific predefined protection goal. Extreme events with intensities that exceed the capacity of these protection structures are called "cases of overload" and are associated with "residual risks" that remain after the implementation of protection measures. In order to address residual risks and to reduce the damages from overload events, a combination of structural protection measures with additional, nonstructural measures is required. Based on data collected through a literature review, a questionnaire survey, expert interviews, and an expert workshop we highlight the status quo as well as key challenges of dealing with residual risks and cases of overload in Alpine countries in the context of geohydrological hazards and gravitational mass movements. We present a holistic conceptual framework that describes the relationships of residual risks, cases of overload, and protection goals in the context of both risk governance and integrated risk management. This framework is valuable for decision makers aiming at an improved management of natural hazards that takes adequate account of residual risk and cases of overload in Alpine countries and mountain areas worldwide.
\end{abstract}

Sönke Hartmann

soenke.hartmann@t-online.de

1 Eurac Research, Institute for Earth Observation, 39100 Bolzano, South Tyrol, Italy

2 Eurac Research, Institute for Regional Development, 39100 Bolzano, South Tyrol, Italy

3 Institute for Environment and Human Security, United Nations University, 53113 Bonn, Germany
Keywords Alpine countries - Cases of overload · Integrated risk management $\cdot$ Natural hazards $\cdot$ Residual risk $\cdot$ Risk governance

\section{Introduction}

Residual risk and cases of overload are still rather new and complex terms for most actors involved in risk management. Consequently, the potential to misinterpret the terms is large. Several authors define residual risk as the risk that remains after the implementation of protection measures (Büchele et al. 2006; Bornstein 2010; BAFU 2016a). Cases of overload are described as rare but very intense events that exceed the capacity of a protective measure (BAFU 2016a; Löschner 2017). How to address residual risk and cases of overload to ensure enough protection for society and infrastructure is a great challenge, in particular in the face of uncertainties related to climatic and sociodemographic changes.

Geohydrological hazards such as river and torrential floods, as well as gravitational mass movements including rockfalls, avalanches, and landslides are common natural threats in the European Alpine region. Alpine communities are well aware of these circumstances, and protecting against these natural hazards has always been part of the Alpine culture (Permanent Secretariat of the Alpine Convention 2019). In Austria, first control measures for slope stabilization were installed as early as 1500 . Since the 1890 s, a combination of biological and technical engineering measures has been established (Holub and Fuchs 2009). Despite further measures during the twentieth century that were aimed at deflecting hazard processes away from residential areas, the amounts of loss and damage due 
to natural hazards and the investments necessary to protect society from them kept increasing.

Changing climatic conditions and related changes in the frequency and intensity of natural hazards represent only two of many reasons for this (EEA 2009, 2010; PLANALP 2012; Knight and Keiler 2013; APCC 2014; Stoffel et al. 2014; EEA 2017; Zebisch et al. 2018). However, mostly due to the increasing number of buildings that are exposed to risk in many Alpine valleys, the costs of protecting society have increased even further (Fuchs et al. 2017). As a result, the need for a reliable set of measures that helps to deal with residual risk and cases of overload became evident and commonly accepted (Loat 2010). Within the frame of an integrated risk management (IRM), stakeholders involved in managing natural hazards developed a comprehensive approach to treat hazards and their related risks with appropriate, systemic actions (FOCP 2014). These measures include hazard zoning, risk communication and hazard alerts, and spatial as well as emergency planning, and have a huge potential to support the authorities in dealing with cases of overload and residual risk. In parallel, the recognition increased that absolute safety could not be achieved. Against this background, IRM represents a useful frame based on which key concepts to deal with residual risk and cases of overload were developed (Holub and Fuchs 2009; Camenzind and Loat 2014; Grobicki et al. 2015). Within the recently published 7th Report on the State of the Alps (Permanent Secretariat of the Alpine Convention 2019), the necessity to discuss residual risk and cases of overload in the context of natural hazard risk governance was addressed accordingly.

In this study, we investigated, analyzed, and present the status quo, as well as key challenges concerning the consideration of residual risk and cases of overload within risk management practices of geohydrological hazards and mass movements in Alpine countries. As part of our results, we present a conceptual framework that visualizes the relevance of these aspects in natural hazard risk management. Further, we argue why this topic is significant not only for political decision makers but for society as a whole and why an improved risk management of natural hazards may contribute to the development of a risk-competent society. This study had two main aims:

- To provide an overview of the status quo of how the terms residual risk and cases of overload in the various Alpine countries are defined and how these concepts are considered within risk management procedures.

- To develop a conceptual framework that improves the understanding of the relationship of residual risk and cases of overload in the context of selected natural hazards.

\section{Methodology}

The study was conducted between March 2017 and March 2018. We carried out four main methodological steps that allowed us to work towards our defined objectives in a coherent and cumulative way: (1) a literature review to gain an extensive overview of risk management practices with respect to residual risk and cases of overload in the Alpine region; (2) development of a questionnaire to collect additional required data and information; (3) selected expert interviews; and (4) an expert workshop to identify research and management gaps, and possibilities to improve the management of residual risk and cases of overload in the context of natural hazards.

Sixty-six experts participated in steps two, three, and four in various ways. Of these 66 experts two participated in both the questionnaire survey and the interviews, eight participated in both the questionnaire survey and the workshop, another two took part in both the interviews and the workshop, and two contributed to this study in all three working steps. The statistics of these experts (country, gender, affiliation, discipline, and experience) are summarized in Sects. 2.2 to 2.4, where each of the working steps is presented in detail.

\subsection{Literature Review}

We carried out a review of existing literature including scientific publications, grey literature, laws, and regulations to gain an overview of the status quo regarding risk governance at different administrative levels (transnational, national, regional, and local) in Alpine countries and the consideration of residual risk and cases of overload in these countries. The reviewed documents were identified with the Google Scholar search engine and the Scopus database, using the keywords "residual risk," "overload," and "Alpine." Additional relevant documents were found on the websites of administrative bodies in the various countries. Overall we identified 72 documents as relevant if two or more of the following criteria applied:

- The country of focus was Alpine (Austria, Italy, Switzerland, Slovenia, Germany, Liechtenstein, or France).

- The type of natural hazard of focus was geohydrological and/or gravitational, including river floods, torrential hazards, avalanches, rockfalls, and landslides.

- A definition for cases of overload and/or residual risk was given.

- A reference to risk governance/management and/or climate change was included.

- Good practices were described. 
We then used spreadsheets to carry out a comparison of the results in order to identify similarities and differences between the Alpine countries. The results of the literature review led to a preliminary overview of the topic at stake, particularly covering the questions of how terms are defined as well as how protection goals are determined. They represented the knowledge base for the development of the questionnaire.

\subsection{Questionnaire Survey}

To collect qualitative and quantitative data about whether and how residual risk and cases of overload are considered within risk governance activities in the Alpine countries, we designed an online questionnaire. The underlying purpose of this questionnaire survey was to reach out to as many experts as possible to receive as complete as possible an overview about the situation in the various Alpine countries. The questionnaire consisted of 54 questions of different kinds (closed, semi-open, open, Likert scale) and covered different aspects relevant to risk governance in the context of residual risk and cases of overload (Table 1).

The questionnaire was addressed to experts working in the field of risk governance of natural hazards at the national and regional levels in all Alpine countries. We sent it to the members of the Natural Hazards Working Group (PLANALP), a thematic working group within the
Alpine Convention, which was set up to develop strategies to address natural hazards in the Alps. We also sent the questionnaire to the members of the international research society Interpraevent and distributed it among the members of the EUSALP Action Group 8, an alpinewide working group that aims to improve risk management and to better manage climate change, including the prevention of major natural risks. In order to involve a wide range of experts, the recipients were asked to spread the survey further among their networks. Consequently, the exact number of recipients is unknown.

Overall, 42 completed questionnaires were returned. The responses came from experts from six of the seven Alpine countries, excluding France. Thus, in all figures in Sect. 3, data from France are absent. Of these 42 experts, 15 came from Austria, 10 from Italy, six from Switzerland, five each from Slovenia and Germany, and one from Liechtenstein. Only two of these experts were female. The majority was either natural scientists (20) or engineers (18) by training. One expert each came from the political sciences, spatial planning, civil protection, and law. The participating experts predominantly represented public authorities at the regional (19) and national levels (14) but also academia (5) and private enterprises (4). Most experts claimed to have more than 10 years of experience (29), while 10 experts stated to have six to 10 years, and three had 3-5 years of experience in their field of expertise.

Table 1 Structure of the online questionnaire on issues of residual risk and cases of overload in the context of managing natural hazards in Alpine countries

\section{General information about the expert}

Geographical scope of answers (national, regional, local) and work (European, transnational, national, interregional, regional, local); country and region of origin; age; education; affiliation; position; field of expertise; working experience

\section{Protection goals}

Type of protection goals used (risk- or hazard-based); differences in protection goals used for different land-use types; adjustment of protection goals

\section{Residual risk and cases of overload}

Existence of definitions; rating whether or not certain events are considered cases of overload; severity of certain problems during cases of overload; rating of the importance of functionalities during cases of overload

\section{Status quo of risk governance}

Departments involved in risk governance of natural hazards; existing task forces; involvement of actors; responsibilities

5 Status quo of risk management

(1) Prevention

(2) Preparedness and response

(3) Recovery

(4) Mitigation

(5) Consideration of climate change

\section{Personal considerations and recommendations}

Importance and agreement of principles to deal with cases of overload and residual risk

7 Collection of good practices 
Based on these statistics, we believe that their answers can be a reliable source for this research.

We analyzed the data collected through the questionnaire survey using the software SPSS and carried out a descriptive statistical frequencies analysis. Given the small sample size and the aims of this study we decided to focus on countries only and not to consider age, regions, or years of experience during our analysis.

\subsection{Expert Interviews}

In order to fill remaining gaps in knowledge areas where the literature review and the subsequent questionnaire survey did not provide exhaustive results, we conducted 20 in-depth interviews with experts (19 male, one female) from the Alpine region in a semistructured format. Because of the missing data from France in the questionnaire survey, we made a special effort to contact French experts for the interviews and were able to carry out three interviews that focused on how cases of overload and residual risks are being dealt with in France. Overall, the interview partners came from all seven Alpine countries (seven from Switzerland, three each from Germany and Italy, two from Austria, and one each from Liechtenstein and Slovenia) and had expertise on at least one of the types of natural hazards covered in this article. The interviewed experts were chosen because of their different geographical scopes, affiliations (seven from national authorities, six from regional authorities, five from academia, and two from private enterprises), disciplines-engineering (11) and natural sciences (9) - and great experience (16 experts had more than 10 years of working experience), which helped us to get further insights into a variety of areas with knowledge gaps.

The interviews were carried out via telephone or Skype and were recorded. They were not transcribed word-forword but summarized noting down the key messages. Based on the notes, we carried out a qualitative content analysis. The results provided a substantial contribution to this research due to the variety of the experts' competencies and more detailed answers compared to the questionnaire.

\subsection{Expert Workshop}

Finally, we conducted an expert workshop with 20 members (three female) of the EUSALP Action Group 8 during their meeting in Innsbruck on 19 September 2017. Six of the participating experts came from Austria, another six from Italy, three from Switzerland, two each from Slovenia and Germany, and one from France. Liechtenstein was not represented in the workshop. While the range of working experiences (14 experts had more than 10 years of experience) and the type of affiliation (18 experts worked for public authorities and only two for research institutes) were rather homogenous, the disciplines the experts represented were quite diverse-engineering (9), natural sciences (5), civil protection (4), and political sciences (2). Based on the questionnaire survey and the interviews, the combined expertise of this group of experts makes the data collected during the workshop a reliable source of information.

During this event, the results of our previous working steps were presented to the participating experts. The discussions with them and their feedback shaped the final version of our conceptual framework. In addition, possible preprepared recommendations on how to better include residual risk and cases of overload in the management of natural hazards in Alpine countries were discussed against the background of our achieved outcomes. The recommendations were modified together and prioritized according to relevance by the experts. They have been published as part of a policy paper for both decision makers and the affected population in all Alpine countries (Schneiderbauer et al. 2018a) and are publicly accessible on the EUSALP website. ${ }^{1}$

\section{Results}

The following results present the most important outcomes from the four working steps described above. First, we present our conceptual framework of residual risk and cases of overload. Then, we present the most relevant data concerning the role of protection goals, the notion of IRM, as well as the underlying concept of risk governance with respect to both, their consideration in the framework, and their significance to this study. Since the four working steps addressed the same overall questions of this study from different angles and with different levels of specificity, the presented results are a conclusion of all applied methods. Exceptions are the figures of Sects. 3.2-3.4, which explicitly represent the results of our questionnaire survey.

With regard to the first aim of the study, our data show that there is not one status quo valid for the Alpine region but that the terms residual risk and cases of overload are defined, established, and dealt with differently in each of the Alpine countries. While most underlying thoughts are very similar, there are many differences in the practical implementation as the following results show.

\footnotetext{
$\overline{1}$ https://www.alpine-region.eu/results/beyond-expected-dealingcases-overload-and-residual-risk-natural-hazards-alpine-region.
} 


\subsection{Conceptual Framework of Residual Risk and Cases of Overload}

Much of the collected data showed that there is only limited and, in parts, even contradictory knowledge about residual risk and cases of overload (this is reflected in the distribution of the answers from the questionnaire survey shown in Fig. 2). But the reviewed literature also showed that definitions for residual risk and cases of overload can vary (Büchele et al. 2006; Bornstein 2010; PLANALP 2012). The same holds true for the understanding of risk governance in each of the Alpine countries (Sect. 3.4). The framework presented here, the second aim of our study, helps to understand better the roles of residual risk and cases of overload within the risk management of natural hazards. It has the potential to contribute to an increased awareness for the need to consider residual risk and cases of overload when preparing for and dealing with the adverse impacts of natural hazards among decision makers and the public alike. It further contributes to an improved comprehension of the terms residual risk and cases of overload among experts, and therefore can be considered a first important step in the discussion on how to include these concepts in existing risk management strategies. It also attempts to clarify the relationship between existing risks, protection goals, and cases of overload, inspired by the underlying thoughts of an IRM. As visualized in Fig. 1, the framework shows the overall complexity of risks in a systemic and simplified way. It aims to represent the whole range of possible hazardous events with different intensities. Within this framework, as indicated in the grey arrow at the bottom of the figure, the process intensity and the damage potential-for example, of an arbitrary type of natural hazard-increase from left to right. While the probability of occurrence decreases with intensity and damage potential, the overall risk in this framework is expected to increase towards the right of the figure.

Potential risks related to damaging consequences of natural hazards are usually defined by the determination of protection goals. In our framework-with reference to Renn et al. (2011, p. 234), who distinguish between simple risks that are known and systemic risks, which are "embedded in the larger contexts of societal processes" and require "a more holistic approach" — we tried to divide the wide range of possible risks into risks that are known, controllable, and intolerable on the left-hand side of the illustration, and remaining risks, including residual ones, characterized as necessarily tolerable and to some extent unknown or not controllable on the right-hand side of the illustration. These two categories of risks are separated by defined protection goals and the protection measures taken to achieve them. On the right-hand (red) side of the framework, those cases whose intensity exceeds the protection measures are called cases of overload and are therefore assigned to the remaining risks. Hence, in our concept, an increase in the designation of a protection goal would lead to a reduction of the space of possibilities of cases of overload and thus reduce the likelihood of residual risks. Assuming other framework conditions as unchanged, the greater protection goals are, the smaller the likelihood of cases of overload will be.
Fig. 1 Conceptual framework of residual risk and cases of overload in the context of risk governance of natural hazards

\section{THE CONCEPT OF RESIDUAL RISK AND THE CASE OF OVERLOAD}

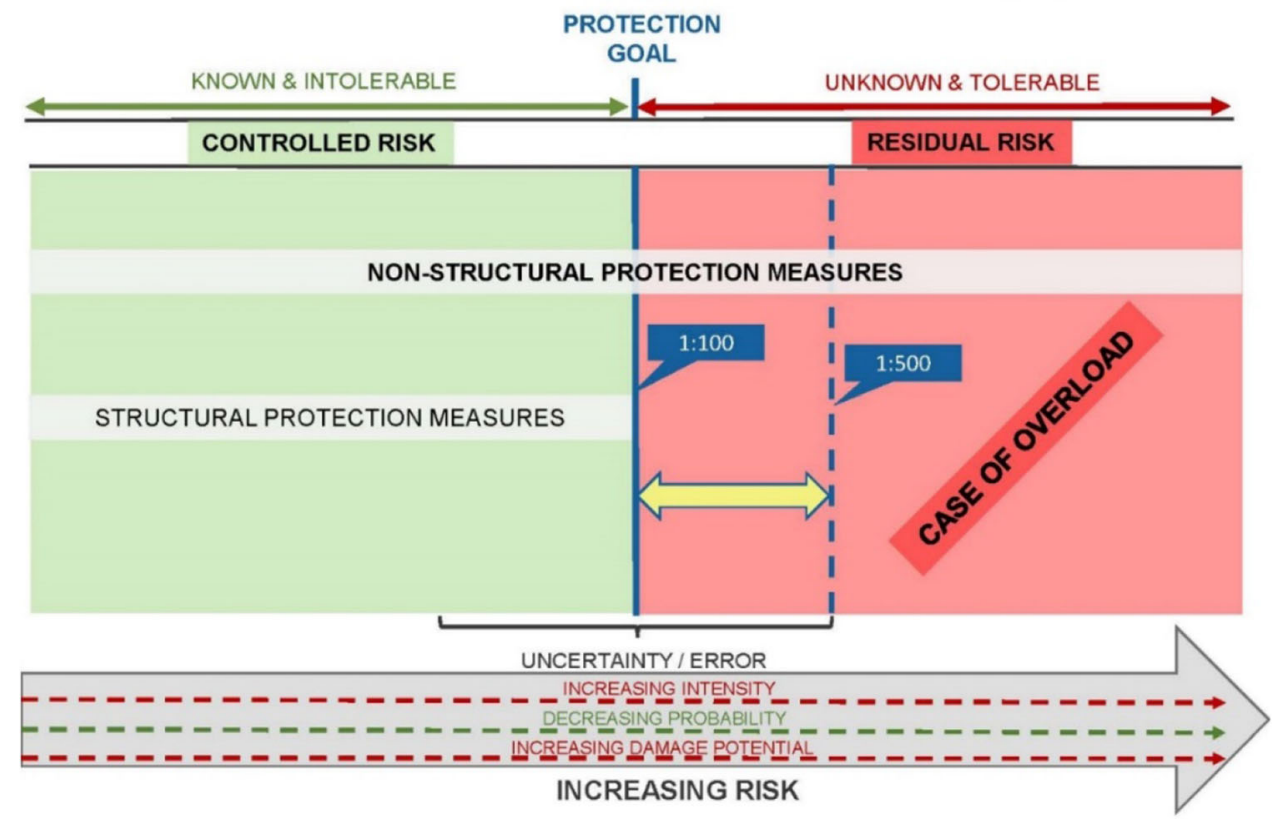


In our framework, such a protection goal is shown as the solid vertical blue line. However, the exact degree of protection that corresponds to the related measures necessary to achieve that protection is subject to change. Due to simplifying model assumptions, limited availability of information, and possibly incorrect calculations, protection goals cannot be calculated very precisely. Thus, they do not represent a fixed value but rather a "blurry" spectrum that is susceptible to uncertainty as indicated by the black bracket labelled "Uncertainty/Error." Nonetheless, protection goals are an essential part of risk governance as they help to make decisions about protective measures and determine what society describes as residual risk and what not.

The core statement of this concept refers, on the one hand, to the possibility of influencing the extent of the remaining risks by defining and possibly increasing a protection goal. On the other hand, the framework shows the limitations of structural measures in risk management. It clarifies that structural measures are linked to defined protection goals. However, nonstructural measures such as spatial planning or risk communication activities may have a positive effect, irrespective of the protection goal (Loat 2010; FOCP 2014; Buchecker et al. 2016; Fuchs et al. 2017). The grey latitudinal bars and the yellow arrow in the figure illustrate this. Structural protection measures such as dams, barriers, and walls primarily help to control risks up to an existing protection goal, which often is specified as a threshold value for events of a certain intensity. In the context of floods, for example, in many settlement areas this may be the intensity of an event that is statistically reached or exceeded every 100 years (1:100). Thus, the protection goal's protective function is limited as it terminates at a specific size of an event, meaning that the measures were built to protect against events of this intensity only. As indicated by the yellow arrow, this threshold is subject to change depending on the level one might want to prepare for. Investing in better structural protection measures to be able to determine higher protection goals may help to control a larger spectrum of risks and prepare for events that statistically occur much less frequently, for example once every 500 years (1:500). Nevertheless, such "grey" approaches usually tend to be very costly and will never be able to cover the whole spectrum of risks. However, in combination with additional nonstructural protection measures, as indicated by the continuous grey latitudinal bar, almost the whole spectrum of risks, including previously residual ones, could be addressed. Such measures include activities related to spatial and contingency planning as well as forecast and warning systems, communication tools, and evacuation procedures. They support affected communities in preparing for unexpected situations including cases of overload and are an essential part of IRM. In addition to the experts consulted for this study, many authors have pointed out the necessity to identify and implement nonstructural protection measures within risk governance of natural hazards (Loat 2010; FOCP 2014; Buchecker et al. 2016; Fuchs et al. 2017).

\subsection{The Role of Protection Goals}

Protection goals are an important cornerstone when dealing with residual risk and cases of overload. Within the reviewed literature, a protection goal is defined as the "level of security that particular responsible actors aim to achieve in their area of responsibility" (PLANAT 2014, p. 4) and used "as a criterion for assessing the need for action to reach the recommended security level." Our data from the literature review show that the definition of a protection goal as a precise threshold value for the occurrence of natural hazard is not a straightforward process. It is important to be aware of the fact that by defining a protection goal, a decision is made up to which extent the responsible authorities aim to guarantee the protection of society, and beyond which threshold value the possible negative effects of potential cases of overload are possibly tolerated (Renn et al. 2011). Thus, the determination of protection goals is not only a question of what is technically feasible. It is much more a balancing-out of financial capacities, the capabilities and willingness of decision makers, as well as the capacities to assess to what extend communities are able to deal with the consequences of residual risks (Permanent Secretariat of the Alpine Convention 2019). Our data from the questionnaire survey reveal that in the different Alpine countries there is a large variety of types of protection goals and procedures to determine them. These differences in protection goals exist between regions and different land-use types and were revealed when asking the experts to indicate which protection goal is used for the different natural processes and whether it is based on risk parameters-such as the exposure and vulnerability of elements at risk such as people, buildings or infrastructure-or the hazard itself (Fig. 2).

While some protection goals in Alpine countries are based on the return periods of specific hazard types, others are determined by risk models and estimated potential impacts of natural hazards. The data of this study showed that protection goals in Austria are set with respect to hazards and dangerous processes, particularly in the case of water-related hazards. This contrasts with Switzerland and to some extent also Italy, where respective protection goals are usually based on risk parameters. However, protection goals regarding avalanches and rockfalls in Austria are based primarily on risk parameters as well. 
Which type of protection goal(s) is/are used for the following natural hazards in your region/country?

(a) River floods

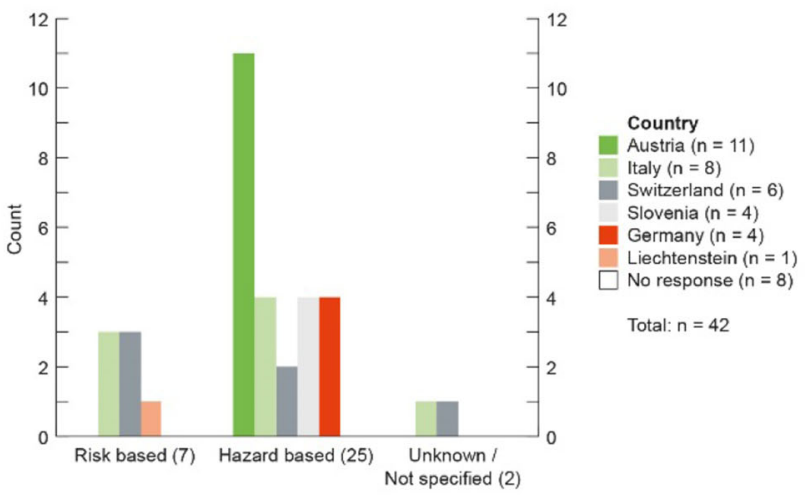

(c) Avalanches

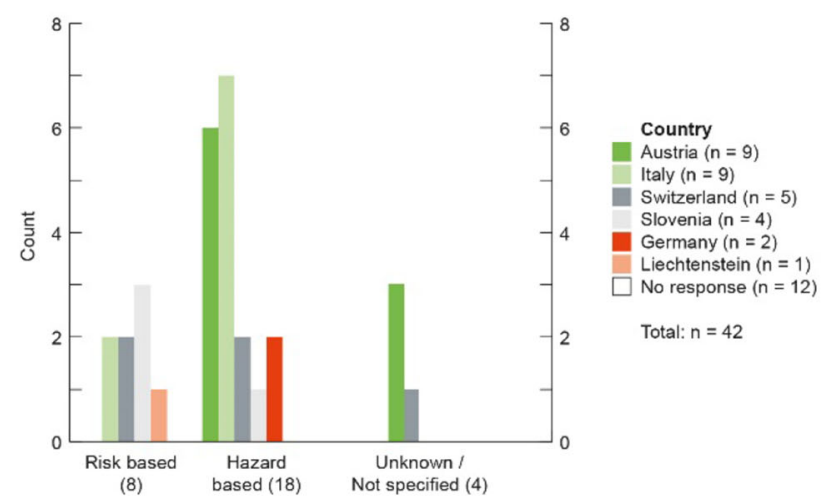

(b) Torrential hazards

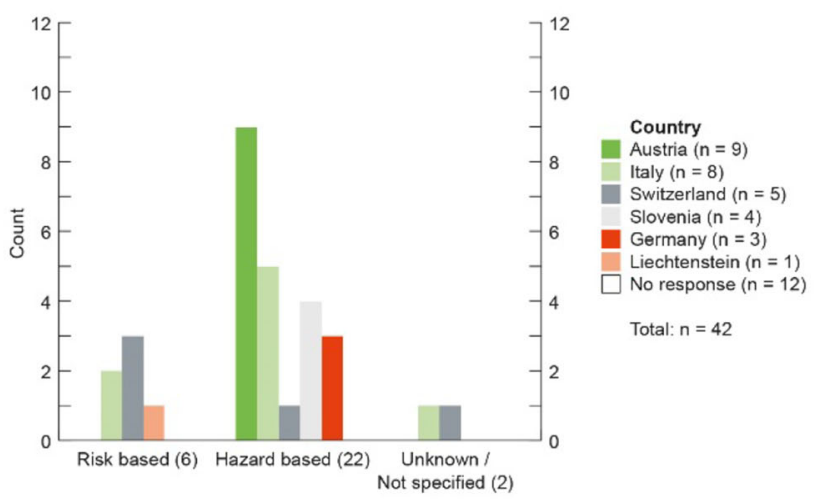

(d) Rockfalls and landslides

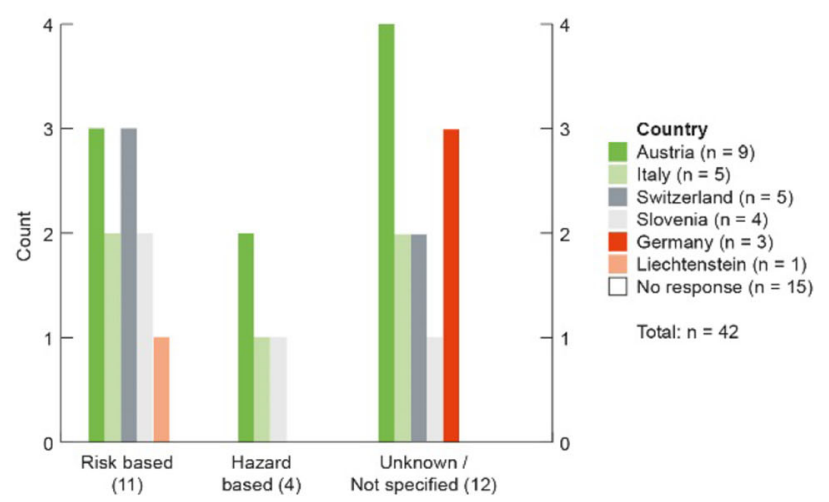

Fig. 2 Determination of protection goals in Alpine countries based on data received from experts who filled out the study questionnaire

Both approaches to determine protection goals are impeded by several challenges, weaknesses, and limitations that were brought up by the experts interviewed for this study and addressed in the reviewed literature. These challenges concern on the one hand data availability and on the other hand political, legal, and social aspects.

Data availability is a key variable for the exact calculation of protection goals and the appropriate design of protection measures. While hazard-based protection goals solely rely on statistical data of a certain hazard type's return period, risk-based protection goals require additional knowledge of risk parameters. Unfortunately, for both hazard-based and risk-based protection goals, data scarcity and resultant uncertainties are persistent challenges, which make it very difficult to carry out correct calculations for the determination of protection goals and the dimensioning of protection measures. The experts interviewed for this study emphasized the necessity of long-term observations as well as a better knowledge of potential future changes concerning the occurrence and intensity of natural hazards that allow for an improved assessment of relevant parameters. To anticipate possible uncertainties and miscalculations, they further suggested considering the potential damages during cases of overload by means of additional engineering safety measures. These measures include, for example, buffer zones near residential areas and dyke improvements along major rivers. According to the experts, such measures would allow for a security margin both now and in the future.

Political and legal prerequisites may constitute weaknesses that prevent foreseen protection goals from being implemented. The consulted experts mentioned financial bottlenecks, difficulties in decision-making processes, and the tendency of politicians to act in response to an event, rather than taking actions beforehand, as challenges when determining protection goals. Due to these circumstances, they argued that further accounting of residual risk and cases of overload when determining protection goals will be necessary in order to reduce disaster risks in the future, raise awareness for this topic, and potentially improve future decision-making and planning processes. According to the experts and the reviewed literature, the awareness among both decision makers and the public concerning the role of protection goals and the potential benefits of 
additional nonstructural protection measures has already increased in recent years in the Alpine region (Camenzind and Loat 2014).

Finally, protection goals are not only set based on statistical calculations. They also take into account several additional factors such as historical records and experiences with previous events, as well as political will and thus decision makers' subjective perceptions of risk, adding to the complexity of protection goal determination (Luhmann 1993; Renn 2005). According to the concept of IRM, determining protection goals represents a common decision that a community makes concerning the provision of safety against natural hazards. It is usually a compromise between competing interests related to economic capacities, environmental and spatial planning, political agendas, as well as technical and engineering parameters.

\subsection{The Link between Integrated Risk Management and Residual Risk}

The role of residual risk is only one aspect of managing natural hazards that needs to be part of a wider approach that consists of a variety of measures. In the literature reviewed for this research, such an attempt-including risk analysis, spatial and emergency planning, and a risk dialogue-is summarized as IRM (PLANALP 2012; FOCP 2014; BAFU 2016b). Integrated risk management is described as a prominent, systematic, and comprehensive approach to address a wide range of hazards and their related risks, if possible with all relevant actors and an appropriate set of transparent measures (FOCP 2014), including many that could be considered "nonstructural" (BAFU 2016b). First pursued at the end of the twentieth century, the development and use of IRM measures in Switzerland are considered exemplary and have shaped the risk governance activities of many countries, particularly in the Alps. Today, IRM can be seen as a key component of the overarching concept of risk governance as it can help to find the most efficient combination of measures to address all principles of risk governance, including risk analysis, risk evaluation, and risk reduction, as well as risk management (Loat 2010; PLANALP 2012). In this research, we incorporate the concept of IRM due to its holistic approach that aims to prepare for all eventualities, including cases of overload and residual risk.

Some authors see a pressing need to apply IRM when dealing with natural hazards (Einhorn and Peisser 2011). According to Loat (2010), an increased awareness and acceptance of residual risk and cases of overload could help to change our current risk culture towards a riskcompetent society, which would support the attempt to reduce loss and damage. Several good practice examples from Alpine countries have shown that there are opportunities to address successfully residual risk and cases of overload by means of IRM measures (Schneiderbauer et al. 2018b). Many of the interviewed experts also mentioned several additional good practice examples that have shown that a combination of technical, nonstructural, nature-based, legal, and institutional measures, as well as measures related to communication activities, offer a number of opportunities to address residual risk and potential cases of overload holistically. The respondents further expressed the usefulness of continuing to invest in nonstructural measures in their questionnaire answers. As shown in Fig. 3, most of the experts either partially or fully agreed that:

- Nonstructural measures should receive greater prioritization in contrast to structural measures (statement a);

- The awareness for residual risks and potential cases of overload must be raised and communicated better (statement b);

- Areas with high residual risk and high potential for cases of overload should not be further developed (statement c); and

- Natural areas with a protective function must be safeguarded better (statement d).

\subsection{Risk Governance in the Context of Residual Risk and Cases of Overload}

Renn and colleagues discussed the meaning of risk governance in the context of the framework introduced by the International Risk Governance Council (IRGC) in several publications (Renn 2008; Renn and Sellke 2011; Renn et al. 2011; Klinke and Renn 2019). According to these authors, risk governance at its core addresses the assessment, management, and communication of all types of risks. Among other goals, risk governance aims to reduce the amount of loss and damage through creating public knowledge, as well as establishing a public discourse about natural hazards and the risks associated with them, thereby fostering regional adaptation measures (Renn 2005, 2008; Renn and Sellke 2011). Risk governance further seeks to develop a functioning risk culture through increasing the participation and awareness of actors (Renn et al. 2011). Hence, it represents a comprehensive process that aims to incorporate all relevant factors into risk-related decision making that may have an influence on successfully addressing natural hazards (Permanent Secretariat of the Alpine Convention 2019).

Within risk governance, residual risks are characterized by complexity, uncertainty, and ambiguity (Renn et al. 2011). Thus, grasping their underlying concepts and integrating them into risk governance activities is all but trivial. The empirical data collected with the questionnaire 
To which degree do you agree to the following possibilities to address risk management/governance in the case of overload and residual risk in your region/country?

(a) Greater prioritization of non-structural measures (in contrast to structural measures).

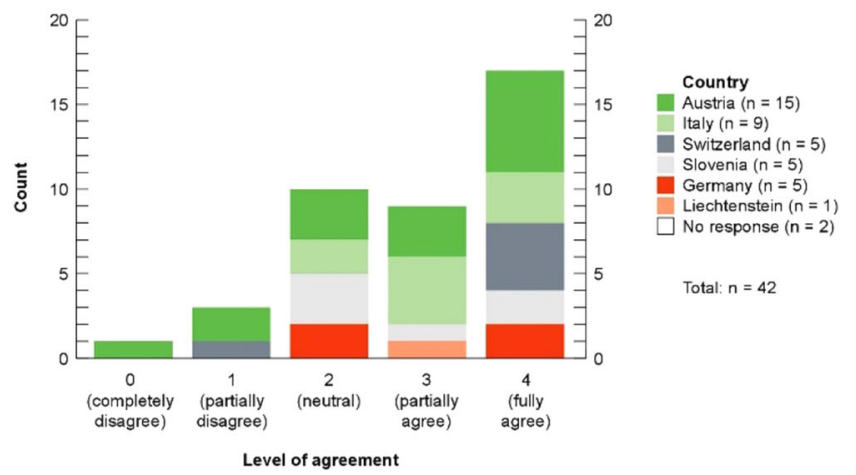

(c) No further development of areas with high residual risk and high potential for cases of overload.

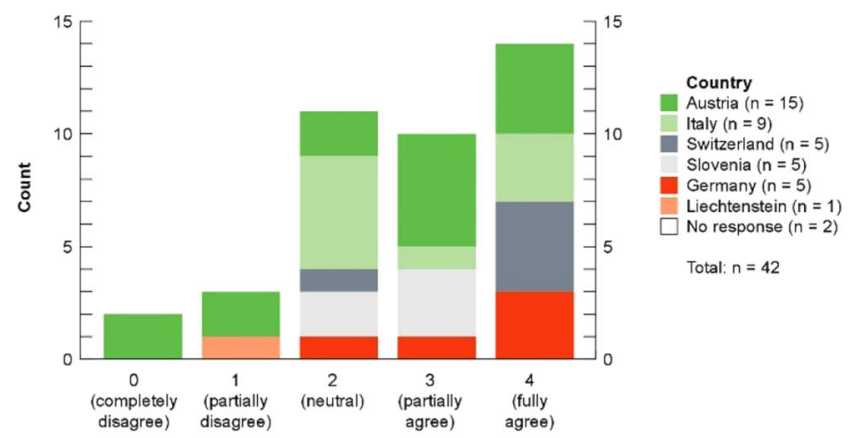

Level of agreement (b) Improved communication of residual risks and the potential cases of overload as well as awareness-raising measures.

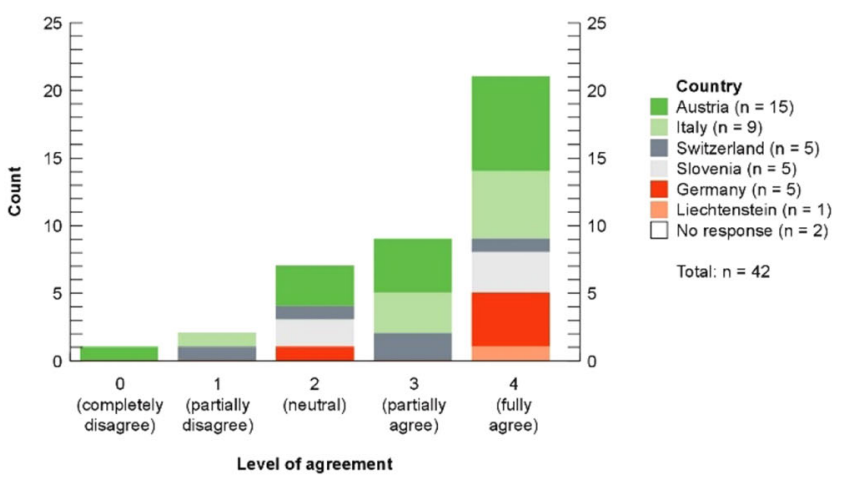

(d) Safeguarding of natural areas with protective function.

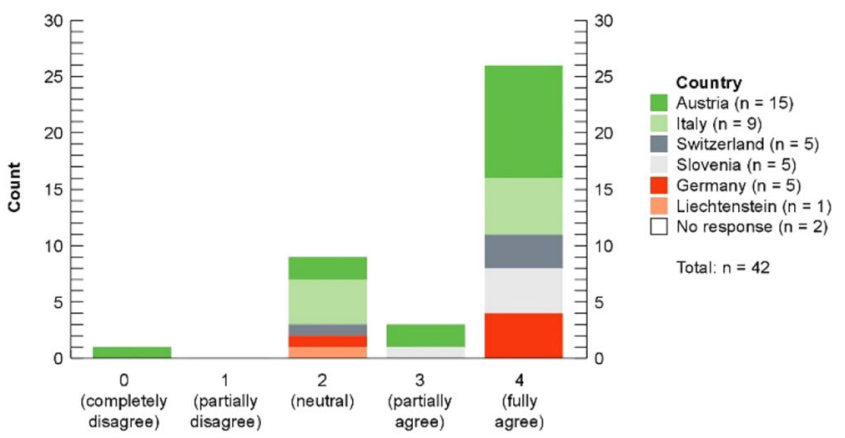

Level of agreement

Fig. 3 Level of agreement from experts who filled out the study questionnaire with respect to possibilities to address cases of overload and residual risk within risk management in Alpine countries

\section{Do definitions for the following terms exist in your region/country?}

\section{(a) Residual risk}

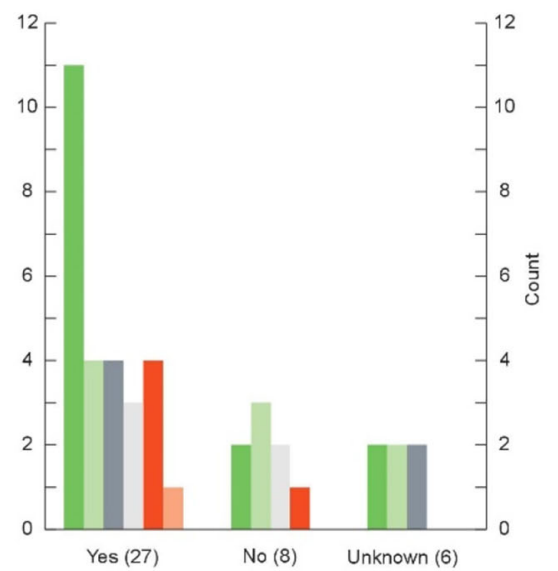

(b) Case of overload

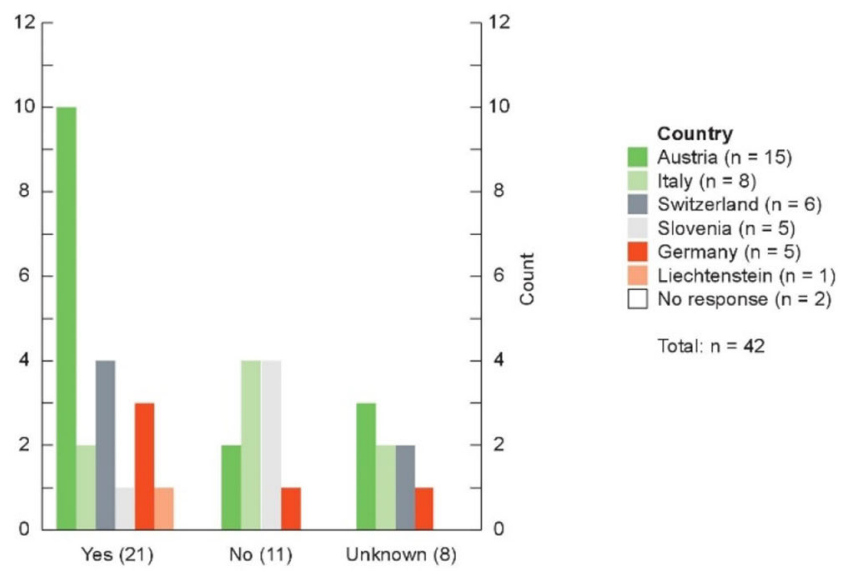

Fig. 4 Existence of definitions for residual risk and case of overload in Alpine countries based on data received from experts who filled out the study questionnaire 
survey showed that the knowledge of the experts about residual risks and cases of overload, as well as current risk governance approaches, varies. As shown in Fig. 4, there seems to be a general common understanding about the existence of definitions for residual risk and cases of overload. Most (27 of 41, one expert did not provide an answer) experts stated that a definition for residual risk exists in their country. For cases of overload, this was the case for 21 of 40 experts (two experts did not respond).

The experts who knew about an existing definition referred to many different documents as their source of information and named differences in the exact terminology as well. Many interviewed experts pointed out that common terminology for both terms could contribute towards an increased awareness and acceptance of residual risks and cases of overload and their importance to risk governance among both decision makers and the public. They added that a common transborder understanding of the terms could be beneficial for the exchange and implementation of methodologies currently applied in risk governance in the Alps.

With respect to the actors involved in risk governance approaches in Alpine countries, the questionnaire data show a discrepancy concerning the type of actors involved, their responsibilities, as well as the methods and tools applied. Although a multidepartment and multiactor risk governance approach is established in each country, the compositions of departments and actors are slightly different (Fig. 5). In all Alpine countries, except Liechtenstein-due to its specific situation as a miniature state-not only spatial planning departments and civil protection are involved in dealing with natural hazards, but also technical and other departments. The same holds true for the type of actors involved in policy-making processes related to risk governance (Fig. 6). While the general composition of actors is similar, there are differences in the detailed composition.

\section{Discussion}

The data collected for this study as well as the conceptual framework may help all actors in Alpine communities to prepare for unexpected events and to increase the awareness of residual risks and cases of overload among both experts and citizens. Currently, even though all Alpine countries intend to implement measures related to IRM, they do not do it in the same way. Instead, the existing differences display a number of challenges, particularly with regard to the integration of residual risk and cases of overload into existing risk governance schemes. Whether or not the different definitions of the terms, the different determination types for protection goals, or the different composition of departments and actors involved is better or worse in any of the Alpine countries than in another is almost impossible to say due to the different legislative and geographical circumstances. In the following, based on our collected data, we discuss aspects that show what exactly should be improved in all of the Alpine countries.

\subsection{Commonly Accepted Terminology for Residual Risk and Cases of Overload and the Need for Communication with the Public}

As the results have shown, the terms residual risk and cases of overload are familiar to most but not all experts. They are also, to some extent, interpreted differently by those who do know them. If even experts cannot agree on a commonly accepted definition for the terms, how can citizens grasp their significance? We consider this a decisive limiting factor, not only for the acceptance of measures and investments to reduce residual risks but also for the efficiency of risk governance activities, and a challenge that needs to be addressed in the future. Explaining the terms is an important part of a much needed, transborder risk dialogue. As of now, the two terms are neither clearly communicated nor universally established within currently existing risk governance schemes. We argue that clear communication and better understanding of the terms residual risk and cases of overload will help to contribute to awareness-raising among experts and citizens and to tackle the challenges described above. We consider improved communication of the two terms a requisite for the development of a risk-competent society. If aware of the whole spectrum of risks, such a risk-competent society represents a great resource that may play an essential role in shaping a system's adaptive capacity towards residual risks. It could help foster the implementation of nonstructural protection measures and contribute to disaster risk reduction in mountain regions worldwide.

\subsection{Integration of Residual Risk and Cases of Overload into Existing Risk Management Practises}

During the expert interviews and the workshop the participants emphasized that residual risk and cases of overload are not yet sufficiently considered within risk management practices. Integrating them into risk management practises is a difficult but important step that calls for measures at different administrative levels, including a detailed analysis of social, economic, and environmental needs as well as the composition of the stakeholders involved in decision-making processes and the distribution of their competencies. This is backed up by our results, which underline that an analysis of all needs, involved 


\section{Which public administration departments are involved in risk governance for each of the following natural hazards? (several answers are possible)}

(a) River floods
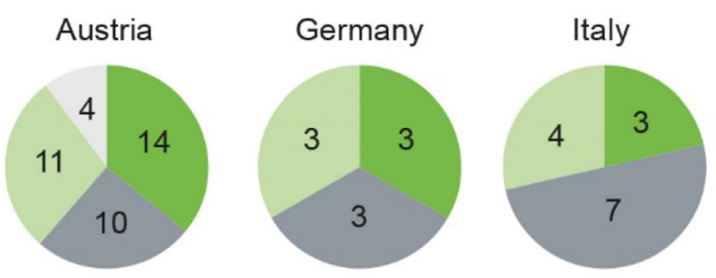

Liechtenstein
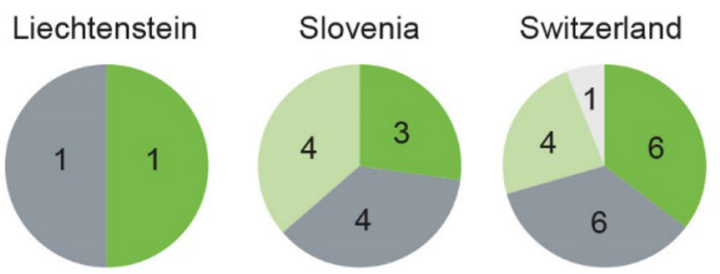

(c) Avalanches
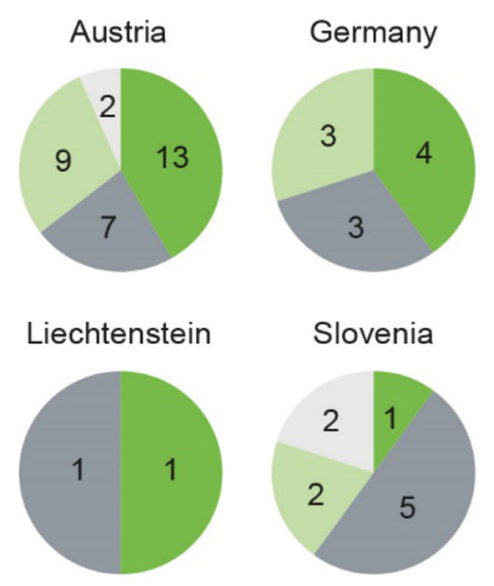

Technical departments

Civil protection

Spatial planning

Other departments
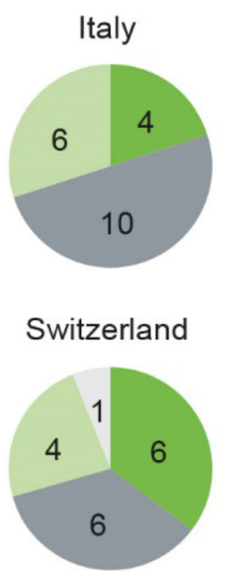

(b) Torrential hazards

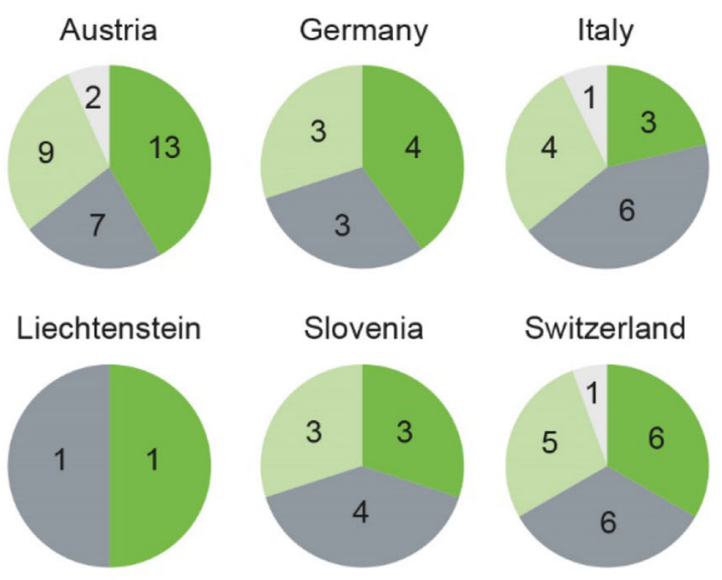

(d) Rockfalls and landslides
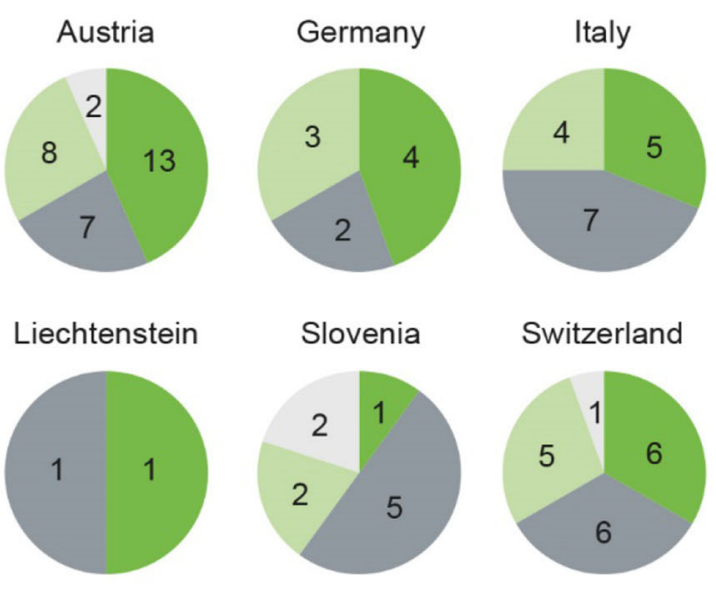

\footnotetext{
Austria $(n=15)$

Italy $(n=10)$

Switzerland $(n=6)$

Slovenia $(n=5)$

Germany $(n=5)$

Liechtenstein $(n=1)$
}

Number of experts per country

Total: $\mathrm{n}=42$

Fig. 5 Departments involved in risk governance of natural hazards in Alpine countries based on data received from experts who filled out the study questionnaire

actors, and existing practices prior to the implementation of measures is required to incorporate residual risk and cases of overload into risk management mechanisms.

\subsection{Collaboration of Actors and their Responsibilities}

Regarding the assumption that a well-working collaboration between actors, the efficient exchange of information, 


\section{Which actors are involved in the process of policy making related to risk governance of natural hazards?}
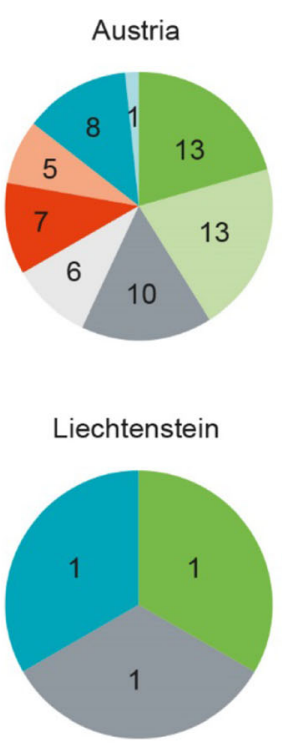
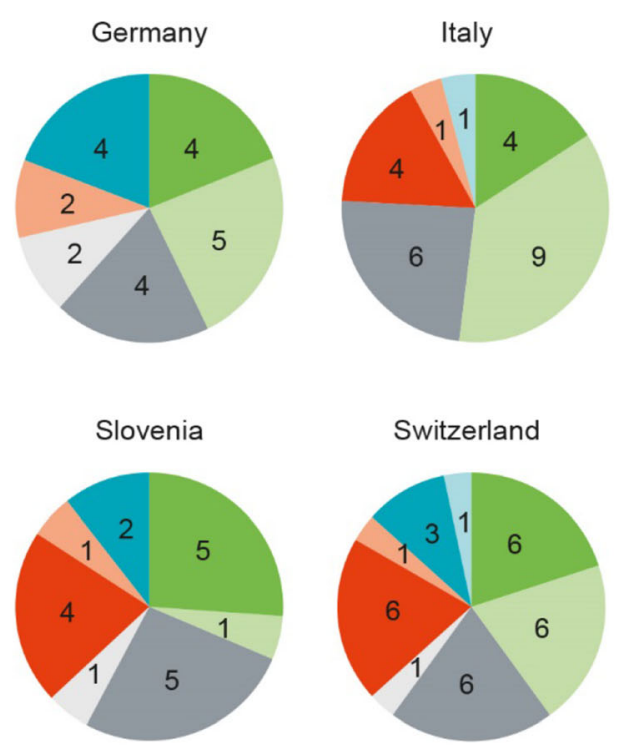

Number of experts

per country

Austria $(n=15)$

Italy $(\mathrm{n}=10)$

Switzerland $(n=6)$

Slovenia $(n=5)$

Germany $(n=5)$

Liechtenstein $(n=1)$

Total: $n=42$

Public administration, national level

Public administration, regional level

Public administration, municipality level

Non-governmental

Organizations (NGO)

Professional associations

Non-professional

associations/federations

Public/civil society

Other actor(s)

Fig. 6 Actors involved in the process of policy making related to risk governance of natural hazards in Alpine countries based on data received from experts who filled out the study questionnaire

and the communication across different administrative levels are key for a successful application of risk governance, several challenges were mentioned in the reviewed literature and in the expert interviews. These challenges include the overlap of administrative tasks, conflicts between government departments due to inefficient communication, and diverging mandates, often resulting in a loss of trust in institutions (Renn et al. 2011). Some of the experts interviewed further mentioned the issue of potential fragmentation of risk governance processes because of missing common goals and policies as well as a potential loss of clarity concerning the share of responsibilities in decision-making processes. Based on these data, we believe that good cooperation among all actors involved in risk governance processes-including planning agencies, political decision makers, civil protection, and the population - would support the successful management of natural hazards and help to build up adaptive capacity, accordingly. This is particularly true and important for risks of transborder, multiple, and cascading hazard types. Their management requires an even better collaboration between multiple actors with clear responsibilities.

Renn et al. (2011) identified a recent change from traditional state-centric systems with hierarchically organized governmental agencies towards multilevel governance approaches in order to distribute the political authority among different public bodies. Our data, concerning the multitude of actors involved in risk governance, confirmed such developments in the Alps, though, as of now, the detailed composition of actors varies slightly.

Besides the variety of actors involved, the interviewed experts mentioned a variety of tools and methods currently used for policy-making processes in the context of natural hazards, including public debates, focus group discussions, referendums, and public as well as online consultations. This variety in approaches, actors, tools, and methods appears very promising for successfully dealing with natural hazards but may also be counterproductive in finding solutions for managing natural hazards, and needs to be analyzed thoroughly.

\subsection{Involvement of the Public}

Based on the interview data, we conclude that not only a multitude of public authorities and departments, but also citizens should play a role in the decision making related to risk governance. By being involved in measures to prevent, plan, and prepare for cases of overload, citizens could help to increase the acknowledgment of overload existence and learn how to deal with cases of overload. Through gaining 
firsthand experiences, citizens will be able to function as multipliers, spreading information and raising awareness about the necessity to consider residual risk and cases of overload within the risk management of natural hazards among their networks. Additionally, such bottom-up initiatives build up trust between affected citizens and relevant authorities and may open everyone's minds towards the benefits of nonstructural measures. Related concepts such as the notion of social innovation (Mosello 2011; Polman et al. 2017) have already shown that-once citizens are aware of certain issues and are given the opportunity to participate-bottom-up approaches and citizenled initiatives have large potential to contribute to approaches currently dominated by institutional character. The idea of more flexible, democratic, and participatory governance designs was broached by Nelson et al. (2007), who argued that if local stakeholders were represented in the implementation of measures, they would be more likely to feel empowered and willing to respond to externally driven changes. In the context of residual risk and cases of overload, this gap has yet to be closed.

\subsection{Critical Reflection of Methodology}

The methodological steps pursued for this research proved to be an efficient way to collect data on this topic in the Alpine region. However, this work is an explorative research that cannot be considered representative for the Alpine region. The presented results only reflect the opinion of experts involved in strategic risk governance tasks at the regional and national levels. The study did not focus on the expertise of citizens, climate scientists, or actors at the municipal level including mayors. Consulting them would have given us even better results and insights on how residual risk and cases of overload are dealt with by different groups within their daily routine and would be very valuable to politicians and decision makers. With respect to the fact that most nonexperts may struggle with the meaning of residual risk and cases of overload or may not even know the terms, the questions asked in the questionnaire and in the interviews lack focusing on the role of citizens and professionals at the local scale.

\section{Conclusion}

The results of this study suggest possible actions to improve dealing with residual risks and cases of overload in the future such as common terminology, cross-border collaboration among experts and relevant authorities, and better communication with and involvement of citizens. The conceptual framework presented in this article is an attempt to visualize the relationship of residual risk, cases of overload, and protection goals in the context of natural hazards management and has great potential to contribute to an improved management of natural hazard risks due to its simple visualization of existing cohesions. The data acquired through the various working steps and the critical discussion with experts from different administrative levels in Alpine countries during the interviews and the workshop showed how the current management of residual risk and cases of overload could be improved, and that for the practical implementation of measures several aspects must be taken into account. This includes that the implementation of measures should always be economically feasible, ecologically justifiable, and socially acceptable. A transparent communication of risks is required, and all actors involved should have a good comprehension of what dealing with residual risk and cases of overload means. To date, the role of citizens within this process is often neglected. In many cases they are the ones most affected yet least aware. Therefore, a target-oriented communication with citizens, in particular at the local scale and with those at risk, as well as further research on this topic, and on other hazards such as heat or drought, is of upmost importance. We consider this research as a first but important contribution towards the much needed, better understanding of residual risk and cases of overload and our results as beneficial for the Alpine society and beyond.

Acknowledgments The content of this article is based on a study carried out between March 2017 and March 2018 as part of the project AlpGov (Implementing Alpine Governance Mechanisms of the European Strategy for the Alpine Region), a project financed by the European transnational cooperation programme Alpine Space within the European Regional Development Fund (ERDF). It supports the work of the EU Strategy for the Alpine Region (EUSALP) in improving the risk governance of natural hazards in the Alps. The study was carried out on behalf of and in close cooperation with the Bavarian State Ministry of the Environment and Consumer Protection (STMUV), which, as a member of and together with the Action Group 8 of the EUSALP, has been working on improving the management of risks related to climate change, including major natural risks prevention. We would like to express our gratitude to Hannah Berger and Andreas Rimböck for guiding us through the stages of this research, for their willingness to always provide us with helpful comments, and for their availability to fruitfully discuss the content whenever needed. We also would like to thank all experts who contributed to this research. All types of contributions-responding to the questionnaire, participating in the interviews, providing background material, and organizing site inspections-were of central importance to our research. Finally, we would like to thank the members of the EUSALP Action Group 8 for having given us the opportunity to discuss our findings during their meeting in Innsbruck on 19 September 2017.

Open Access This article is licensed under a Creative Commons Attribution 4.0 International License, which permits use, sharing, adaptation, distribution and reproduction in any medium or format, as long as you give appropriate credit to the original author(s) and the source, provide a link to the Creative Commons licence, and indicate 
if changes were made. The images or other third party material in this article are included in the article's Creative Commons licence, unless indicated otherwise in a credit line to the material. If material is not included in the article's Creative Commons licence and your intended use is not permitted by statutory regulation or exceeds the permitted use, you will need to obtain permission directly from the copyright holder. To view a copy of this licence, visit http://creativecommons. org/licenses/by/4.0/.

\section{References}

APCC (Austrian Panel on Climate Change). 2014. Austrian progress report on climate change 2014 (Österreichischer Sachstandsbericht Klimawandel 2014). Vienna: Verlag der Österreichischen Akademie der Wissenschaften (in German).

BAFU (Federal Office for the Environment (Bundesamt für Umwelt)). 2016a. From risk analysis to planning of measures-Working basis for flood protection projects (Von der Risikoanalyse zur Massnahmenplanung-Arbeitsgrundlage für Hochwasserschutzprojekte). Bern: BAFU (in German).

BAFU (Federal Office for the Environment (Bundesamt für Umwelt)). 2016b. Protection against mass movement hazards. Enforcement aid for the risk management of landslides, rockfalls and debris flows (Schutz vor Massenbewegungsgefahren. Vollzugshilfe für das Gefahrenmanagement von Rutschungen, Steinschlag und Hangmuren). Bern: BAFU (in German).

Bornstein, C. 2010. Flexible and good-natured protection concepts and structures-An answer to the case of overload and uncertain design bases (Flexible und gutmütige Schutzkonzepte undbauwerke-Eine Antwort auf den Überlastfall und unsichere Bemessungsgrundlagen). Diploma thesis, Technical University Munich, Germany (in German).

Buchecker, M., D.M. Ogasa, and E. Maidl. 2016. How well do the wider public accept integrated flood risk management? An empirical study in two Swiss Alpine Valleys. Environmental Science \& Policy 55(2): 309-317.

Büchele, B., H. Kreibich, A. Kron, A. Thieken, J. Ihringer, P. Oberle, B. Merz, and F. Nestmann. 2006. Flood-risk mapping-Contributions towards an enhanced assessment of extreme events and associated risks. Natural Hazards and Earth System Sciences 6(4): 485-503.

Camenzind, R., and R. Loat. 2014. Risk-based spatial planning: Synthesis report on two case studies at communal land use planning level. Bern: National Platform for Natural Hazards, Federal Office for Spatial Development, and Federal Office for the Environment.

EEA (European Environmental Agency). 2009. EEA signals 2009Key environmental issues facing Europe. Copenhagen: EEA.

EEA (European Environmental Agency). 2010. EEA signals 2010Biodiversity, climate change and you. Copenhagen: EEA.

EEA (European Environmental Agency). 2017. Climate change adaptation and disaster risk reduction in Europe. Enhancing coherence of the knowledge base, policies and practices. EEA report 15. Copenhagen: EEA.

Einhorn, B., and C. Peisser. 2011. Adaptation of natural risk management in the face of climate change (Adaptation de la gestion des risques naturels face au changement climatique). Contribution to the International Expert Seminar "Adaptation to Climate Change in the Alpine Space”, 25 November 2011, L'Argentière la Béssée, France (in French).

FOCP (Federal Office for Civil Protection). 2014. Integrated risk management-Its importance in protecting people and their livelihoods. Bern: FOCP.
Fuchs, S., V. Röthlisberger, T. Thaler, A. Zischg, and M. Keiler. 2017. Natural hazard management from a coevolutionary perspective: Exposure and policy response in the European Alps. Annals of the American Association of Geographers 107(2): 382-392.

Grobicki, A., F. MacLeod, and F. Pischke. 2015. Integrated policies and practices for flood and drought risk management. Water Policy 17(S1): 180-194.

Holub, M., and S. Fuchs. 2009. Mitigating mountain hazards in Austria-Legislation, risk transfer and awareness building. Natural Hazards and Earth System Sciences 9(2): 523-537.

Klinke, A., and O. Renn. 2019. The coming age of risk governance. Risk Analysis. https://doi.org/10.1111/risa.13383.

Knight, J., and M. Keiler. 2013. Impacts of recent and future climate change on natural hazards in the European Alps. In Climate forcing of geological hazards, ed. B. McGuire, and M. Maslin, 223-249. London: Wiley-Blackwell.

Loat, R. 2010. Risk management of natural hazards in Switzerland. Bern: Federal Office for the Environment.

Löschner, L., M. Herrnegger, B. Apperl, T. Senoner, W. Seher, and H.P. Nachtnebel. 2017. Flood risk, climate change and settlement development. A micro-scale assessment of Austrian municipalities. Regional Environmental Change 17(2): 311-322.

Luhmann, L.1993. Risk: A sociological theory. New York: Aldine de Gruyter.

Mosello, B. 2011. Climate change and patterns of governance in Alpine regions. The case of water management in the Aosta and Ossola Valleys. Contribution to the EUSA 12th Biennial International Conference, 3-5 March 2011, Boston, USA.

Nelson, D.R., W.N. Adger, and K. Brown. 2007. Adaptation to environmental change: Contributions of a resilience framework. Annual Review of Environment and Resources 32: 395-419.

Permanent Secretariat of the Alpine Convention. 2019. Natural hazard risk governance-Report on the State of the Alps. Alpine signals, special edition 7. Innsbruck, Austria: Permanent Secretariat of the Alpine Convention.

PLANALP (Platform on Natural Hazards of the Alpine Convention). 2012. Alpine strategy for adaptation to climate change in the field of natural hazards. Bern: PLANALP.

PLANAT (National Platform for Natural Hazards). 2014. Strategy protection against natural hazards. Security level for natural hazards. Bern: PLANAT.

Polman, N., W. Slee, T. Kluvánková, M. Dijkshoorn, M. Nijnik, V. Gezik, and K. Soma. 2017. Classification of social innovations for marginalized rural areas. SIMRA (Social Innovation in Marginalised Rural Areas). http://www.simra-h2020.eu/wp-con tent/uploads/2017/09/D2.1-Classification-of-SI-for-MRAs-inthe-target-region.pdf. Accessed 10 Nov 2020.

Renn, O. 2005. White paper on risk governance-Towards an integrative approach. Geneva: IRGC (International Risk Governance Council).

Renn, O. 2008. Risk governance-Coping with uncertainty in a complex world. London: Earthscan.

Renn, O., and P. Sellke. 2011. Risk, society and policy making: Risk governance in a complex world. International Journal of Performability Engineering 7(4): 349-366.

Renn, O., A. Klinke, and M. van Asselt. 2011. Coping with complexity, uncertainty and ambiguity in risk governance: A synthesis. Ambio 40(2): 231-246.

Schneiderbauer, S., S. Hartmann, C. Dalla Torre, N. Dinkelaker, A. Sankowsky, C. Hoffmann, L. Pedoth, and T. Streifeneder. 2018a. Natural hazards in the Alpine region: Dealing with cases of overload and the residual risk. Munich: Bayarian State Ministry for the Environment and Consumer Protection (Bayerisches Staatsministerium für Umwelt und Verbraucherschutz). 
Schneiderbauer, S., H. Berger, S. Hartmann, A. Rimböck, C. Dalla Torre, and L. Pedoth. 2018b. Dealing with residual risk: Situation analysis and challenges in the Alpine space (Der Umgang mit verbleibendem Risiko: Situationsanalyse und Herausforderungen im Alpenraum). In Regional risk governance: Law, policy and practice (Regionale Risiko Governance: Recht, Politik und Praxis), ed. A. Kanonier, and F. Rudolf-Miklau, 541-553. Vienna: Verlag Österreich (in German).
Stoffel, M., D. Tiranti, and C. Huggel. 2014. Climate change impacts on mass movements-Case studies from the European Alps. Science of the Total Environment 493: 1255-1266.

Zebisch, M., R. Vaccaro, G. Niedrist, S. Schneiderbauer, T. Streifeneder, M. Weiß, A. Troi, K. Renner, et al. 2018. Climate report-South Tyrol (Klimareport-Südtirol). Bolzano: Eurac Research (in German and Italian). 